\section{Commentary: Are we wrapping up the debate on repair of giant paraesophageal hernia?}

\author{
Arya Pontula, BSPH, and \\ Matthew G. Hartwig, MD, MHS
}

Herein, Alicuben and colleagues ${ }^{1}$ describe their experience with repair of giant paraesophageal hernia (GPEH) and provide 10 key steps of their surgical technique. The authors continue to refine their approach since their first report in $2000,{ }^{2}$ summarizing the overarching principles of the procedure to optimize outcomes for operative repair of GPEH. Specifically, the authors advocate 3 key principles: (1) aggressive mediastinal mobilization, (2) assessment of esophageal length, and (3) preservation of the crural lining. ${ }^{1}$ Low recurrence rate and optimal outcomes are also attributed to "careful selection" of adjunct techniques, such as fundoplication, gastropexy, and gastroplasty.

Alicuben and colleagues ${ }^{1}$ perform fundoplication to prevent reflux. However, the decision to routinely provide a fundoplication remains debatable. Recent work evaluating the physiologic impact of hernia repair suggests that the vast majority of the antireflux mechanism is accomplished by the crural closure, rather than by the fundoplication. ${ }^{3}$ This indicates that fundoplication may not be routinely needed if gastroesophageal reflux disease is not a presenting symptom or if fundoplication does not decrease recurrence rate compared with primary repair alone. ${ }^{4}$ When fundoplication is selected, many surgeons prefer a total fundoplication. However, evidence does not suggest an advantage among fundoplication types in reflux and dysphagia prevention, ${ }^{5}$ and preoperative manometry in the setting of a large hernia is notoriously inaccurate. Therefore, it may be

\footnotetext{
From the Division of Cardiovascular and Thoracic Surgery, Duke University Medical Center, Durham, NC.

Disclosures: The authors reported no conflicts of interest.

The Journal policy requires editors and reviewers to disclose conflicts of interest and to decline handling or reviewing manuscripts for which they may have a conflict of interest. The editors and reviewers of this article have no conflicts of interest.

Received for publication Aug 21, 2021; revisions received Aug 21, 2021; accepted for publication Aug 26, 2021; available ahead of print Sept 2, 2021.

Address for reprints: Matthew G. Hartwig, MD, MHS, Division of Cardiovascular and Thoracic Surgery, DUMC, Box 3863, Durham, NC 27710 (E-mail: matthew. hartwig@duke.edu).

JTCVS Techniques 2021;10:505-6

2666-2507

Copyright (C) 2021 The Author(s). Published by Elsevier Inc. on behalf of The American Association for Thoracic Surgery. This is an open access article under the CC BY-NC-ND license (http://creativecommons.org/licenses/by-nc-nd/4.0/).

https://doi.org/10.1016/j.xjtc.2021.08.040
}

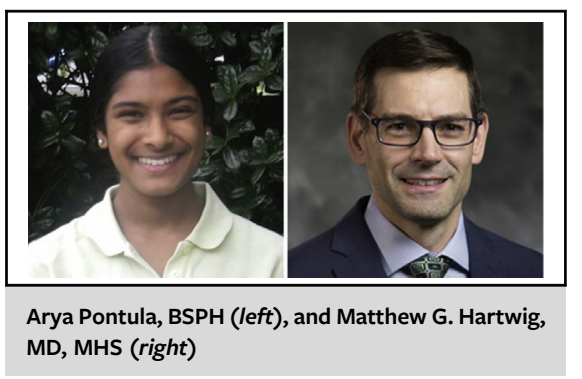

\begin{abstract}
CENTRAL MESSAGE
Careful, evidence-based selec-

tion of adjunct techniques,

particularly fundoplication, gas-

tropexy, and Collis gastroplasty, is

key to reducing recurrence rates

in laparoscopic repair of GPEH.
\end{abstract}

prudent to select fundoplication as an adjunctive technique less frequently, particularly in those with obstructive symptoms, as Alicuben and colleagues ${ }^{1}$ recommend.

Regardless of symptomatology, anterior gastropexy may reduce recurrence rate, ${ }^{6}$ and thus may be an important consideration for all patients. In addition, for patients at high operative risk due to severe medical comorbidities, gastropexy alone may be a reasonable alternative to formal GPEH repair. ${ }^{7}$ Thus, we should consider how gastropexy is used to reduce recurrence rate of GPEH repair for all patients, remembering that not all gastropexy techniques are equal.

The authors suggest wedge-type Collis gastroplasty for patients with a foreshortened esophagus. ${ }^{1}$ This choice aligns with earlier reports of gastroplasty in GPEH repair. ${ }^{8}$ However, esophageal shortening has been attributed to the stomach pushing the esophagus into the chest, rather than to chronic reflux esophagitis, scarring, or pulling of the stomach into the chest. Regardless, gastroplasty should be uncommonly required if repair focuses on correcting the anatomy of the gastroesophageal junction and mediastinal mobilization allows appropriate abdominal esophageal length. ${ }^{6}$

Alicuben and colleagues ${ }^{1}$ describe their standard practice to complete fundoplication before cruraplasty, although many surgeons tend to perform cruraplasty first to estimate esophageal length. The authors also describe their method of creating a floppy diaphragm in reapproximation of the crura by inducing a carbon dioxide pneumothorax. Evidence does not yet exist for the implication of this technique 
on recurrence, but it does provide significant tension release during crural closure. An alternative method, the diaphragm-relaxing incision, has been associated with low recurrence rate, but can also be associated with an alternative site of diaphragmatic weakness. ${ }^{9}$ In summary, Alicuben and colleagues ${ }^{1}$ carefully detail the steps of their operative technique as well as their considerations in choosing adjunct procedures to optimize outcomes for patients suffering with GPEH.

\section{References}

1. Alicuben ET, Luketich JD, Levy RM. Laparoscopic repair of giant paraesophageal hernia. J Thorac Cardiovasc Surg Tech. 2021;10:497-502.

2. Luketich JD, Raja S, Fernando HC, Campbell W, Christie NA, Buenaventura PO, et al. Laparoscopic repair of giant paraesophageal hernia: 100 consecutive cases. Ann Surg. 2000;232:608-18.
3. Stefanova D, Limberg JN, Ullmann TM, Liu M, Thiesmeyer JW, Beninato T, et al Quantifying factors essential to the integrity of the esophagogastric junction during antireflux procedures. Ann Surg. 2020;272:488-94.

4. Solomon D, Bekhor E, Kashtan H. Paraesophageal hernia: to fundoplicate or not? Ann Transl Med. 2021;9:902.

5. Andolfi C, Plana A, Furno S, Fisichella PM. Paraesophageal hernia and reflux prevention: is one fundoplication better than the other? World J Surg. 2017;41: 2573-82.

6. Ponsky J, Rosen M, Fanning A, Malm J. Anterior gastropexy may reduce the recurrence rate after laparoscopic paraesophageal hernia repair. Surg Endosc. 2003; 17:1036-41.

7. Bruenderman EH, Martin RCG, Kehdy FJ. Outcomes after laparoscopic gastropexy as an alternative for paraesophageal hernia repair. JSLS. 2020;24: e2020.00059.

8. Swanstrom LL, Marcus DR, Galloway GQ. Laparoscopic Collis gastroplasty is the treatment of choice for the shortened esophagus. Am J Surg. 1996;171:477-81.

9. Abdelmoaty WF, Dunst CM, Filicori F, Zihni AM, Davila-Bradley D, Reavis KM, et al. Combination of surgical technique and bioresorbable mesh reinforcement of the crural repair leads to low early hernia recurrence rates with laparoscopic paraesophageal hernia repair. J Gastrointest Surg. 2020;24:1477-81. 